\title{
SISTEMATIZAÇÃO DA ASSTISTÊNCLA À GESTANTE DE ALTO RISCO: ESTRATÉGIA PARA O ENSINO DE ENFERMAGEM OBSTÉTRICA
}

Neide de Souza Prafa*

PRAÇA, N. S. Sistematização da assistência à gestante de alto risco: estratégia para o ensino de Enfermagem Obstétrica. Rev Esc.Enf.USP, v.28, n.1, p. 96-104, abril, 1994.

$O$ presente estudo descreve uma experiencia de ensino utilizando a sistematizaçào da assistência de enfermagem aplicada a gestantes de alto risco internadas em uma maternidade. Mostra também a opiniāo dos alunos sobre o emprego desta metodologia.

UNITERMOS: Enfermagem obstétrica. Processo de Enfermagem.

\section{INTRODUÇĀO}

A gravidez, embora considerada como um fenômeno fisiológico, pode apresentar complicaçōes motivadas por condiçōes anormais que surgem ou se agravam durante o periodo gestatório.

Patologias caracterizadas pela cronicidade, infecçöes agudas intercorrentes ou patologias associadas à gravidez, por afetarem sistemas selecionados e alterarem suas funçōes podem colocar em risco a vida da mulher e como conseqüência, de seu concepto. Uma vez detectado o risco de morbi-mortalidade materno-fetal no curso de uma gestaçāo, esta gestante deve ter sua condição rigorosamente avaliada e acompanhada.

Esta situaçāo requer a realizaçāo de exames específicos que possibilitem detectar o agravamento da condição que colocaria em risco a viabilidade fetal ou mesmo a vida materna. Quando o controle da gravidez de risco em nível ambulatorial é prejudicado, faz-se necessária a internaçāo da gestante, a fím de evitar-se complicaçōes, de facilitar sua avaliação e seu tratamento.

Avaliaçāo médica sistemática das complicaçōes que se apresentam ou que possam vir a ocorrer deve ser rigorosamente efetuada durante o acompanhamento desta gestante. Nesta ocasiāo, a análise da patologia manifesta,

Enfermeira. Mestre em Enfermegem. Professor Assistente do Departamento de Enfermagem Materno-Infantil e Psiquiátrica da Eacola de Enfermagem da Univeraidade de Sáo Paulo. Disciplina de Enfermagem Ginecologica, Obstétrica e Neonatal. 
bem como o modo como afeta ou interfere na fisiologia normal da gravidez deve ser altamente valorizada.

A enfermagem participa dessa atençāo à gestante de alto risco através da a tuação em nível ambulatorial e de unidade de internação. Nesta, 0 ato de cuidar pode ser desenvolvido através da sistematização da assistência de enfermagem. Instituiçōes que dispōem de serviços especializados de atenção ao adulto e à criança, aos poucos, vêm implantando esta modalidade de assistência, com adaptação das fases do processo de enfermagem proposta por HORTA (1979) à sua realidade.

Pelas características individuais da gestante e em especial da gestante de alto risco, cujas preocupaçōes com o sucesso da gestação se acumulam frente às complicaçōes que está sujeita, a sistematização da assistência de enfermagem é um valioso instrumento que fornece visão global da condiçāo do binômio mãe-feto, favorece a continuidade de sua assistência, e a direciona através de um embasamento científico (WALDOW, 1988).

\section{LOCAL}

Por acreditar na afirmação acima, a disciplina Enfermagem Obstétrica de uma escola de enfermagem pública da cidade de São Paulo utiliza como campo de prática para o curso de Especialização em Enfermagem Obstétrica, uma maternidade pública que atende em nível terciário, clientela, em sua maioria, constituída por gestantes de alto risco.

Para o atendimento das gestantes que, por somarem patologias à gestação, necessitam de internação prolongada, a citada maternidade dispōe de uma unidade que comporta 18 leitos para grávidas em regime de internação. Nesta unidade näo há limite de tempo para a gestante permanecer internada, e sua alta ocorre quando sāo controladas as complicaçōes pertinentes à patologia, ou quando a mulher entra em trabalho de parto, espontâneo ou induzido. O programa educativo da unidade procura ocupar a gestante com atividades manuais, ao mesmo tempo em que a equipe multiprofissional a informa sobre exames, tratamentos, evolução e prognóstico da gravidez.

Como rotina deste serviço, as gestantes são submetidas a acompanhamento clínico e obstétrico e participam de reuniōes com a equipe multiprofíssional. Neste contexto, a enfermagem presta assistência direta à gestante, bem como colabora e acompanha em seus exames subsidiários, promove o autocuidado e realiza orientaçōes, individuais ou em grupos, sobre higiene, modificaçōes e desconfortos da gravidez.

É nesta unidade que o aluno do curso de Especializaçāo em Enfermagem Obstétrica é inserido por duas semanas, durante o segundo semestre do ano letivo. Cada aluno é responsável por um máximo de seis gestantes ao dia, no horário de 7 às 13 horas, permanecendo com a mesma paciente, no mínimo, por três dias, ao término dos quais, rodizia com o colega na escala do cuidado. 


\section{SISTEMATIZAÇĀO DA ASSISTÊNCIA E O ENSINO DE ENFERMA- GEM OBSTÉTRICA À GESTANTE DE ALTO RISCO}

Como estratégia de ensino para o aluno estagiário, adotou-se a sistematização da assistência de enfermagem à gestante de alto risco a ser desenvolvida para com todas as gestantes da unidade.

Devido à diversidade de patologias que afetam as gestantes internadas nessa unidade e, com o objetivo de individualizar a assistência e de facilitar o aprendizado do cuidado à gestante de alto risco, os alunos desenvolvem a sistematização da assistência preenchendo impresso próprio (Anexo).

Cabe ressaltar que a instituição não adota esta metodologia, embora demonstre interesse em fazê-lo.

Para conhecer globalmente a cliente, no primeiro dia de conta to do aluno com a gestante, aquele verifica, pela análise do prontuário médico, o histórico clínico e obstétrico, pregresso e atual, da gestante. Os dados são registrados conforme os itens constantes no roteiro próprio, elaborado pela autora deste artigo: Sistematização da Assistência de Enfermagem à gestante de alto risco (Anexo I). De posse dos dados referentes à condição clínica e obstétrica da gestante, o aluno realiza exame físico e obstétrico, do qual constam a verificação das condiçōes de pele, tegumento e mucosas de seus parâmetros vitais, do funcionamento de aparelhos e hábitos. Ao exame obstétrico é realizada a palpaçāo de mamas, verificada a condição dos mamilos e da genitália externa, verificadas as medidas da altura uterina e da circunferência abdominal; realizadas também palpação e ausculta dos batimentos cárdio-fetais. Neste momento, de maneira informal, o aluno observa e procura identificar queixas e preocupaçōes da gestante, embora a manifestaçāo destes possa não ocorrer durante este primeiro contato, porém a gestante pode revelá-las nos dias subseqüentes, quando sentir confiança e segurança em relação ao aluno.

Com os dados coletados nas fases anteriores, 0 aluno passa à sua a nálise e a partir dos problemas e necessidades identificados, clínicos e obstétricos, efetua o diagnóstico que embasará a elaboração do plano de cuidados. A prescriçāo das açōes de enfermagem, com base no diagnóstico, é realizada e atendida pelo próprio aluno, diariamente, durante seu período de estágio. Constam também da prescriçāo, a observaçāo de alteraçōes que podem ser verificadas na gestante frente às medicaçōes que ingere, cujas reaçōes podem trazer desconfortos à própria gestante e ou prejuízos ao feto. Constam também orientaçōes individuais. A evoluçāo clínica e obstétrica, diária, é feita pelo aluno após prestar o cuidado e verificar a condição da gestante frente a cada item prescrito.

O impresso utilizado pelos alunos nāo é incorporado ao prontuário da gestante por näo fazer parte da documentação da unidade. Permanece em poder de cada aluno que o entrega ao colega para continuidade na ocasiāo do rodízio de escala. O cuidado prescrito em cada plano direciona a assistência a ser dada pelo aluno, sem que haja qualquer seguimento pelo pessoal de enfermagem da unidade. 
Diariamente, após o aluno prestar os cuidados por ele prescritos no dia anterior, evoluir e atualizar a prescrição de enfermagem, cada plano de cuidados é discutido entre o aluno e a docente que o supervisiona durante o estágio. Nesta oportunidade, o plano efetuado é analisado, realçando seus pontos prioritários, tendo por base a patologia manifesta, as medicaçōes prescritas pela equipe médica, os parâmetros vitais maternos e fetais, os resultados de exames obstétricos e laboratoriais, os aspectos psicossociais da gestante e seu estado geral.

Como complementação da estratégia de ensino adotada, diariamente, o grupo de alunos realiza estudos de caso das gestantes internadas. Neste momento são analisados a evolução e o prognóstico da gravidez frente aos exames e tratamentos específicos efetuados para controle das patologias presentes. Este estudo de caso possibilita a fundamentação prática da teoria verificada nos livros-texto, com realce na interferencia dos sinais e sintomas determinados pela patologia durante o ciclo grávido-puerperal. Possibilita, ainda, avaliar as repercussōes de cada patologia sobre o organismo materno e sobre o feto/recém-nascido.

Embora a sistematização da assistência seja realizada apenas pelos alunos, sem continuidade pelo pessoal de enfermagem da unidade, acreditase que o mesmo, como instrumento de ensino, favoreça o despertar do aluno para a individualização da assistência a cada gestante de alto risco internada, sob seus cuidados, $e$, também para a fundamentaçāo científica sobre os sina is e sintomas próprios de cada patologia. Favorece ainda, a ampliaçāo da visão do aluno para as repercussōes da doença sobre o organismo materno.

Com o intuito de conhecer a opiniāo do aluno sobre a aplicaçāo da sistematização da assistência de enfermagem à gestante de alto risco (ANEXO I), em regime de internaçāo, solicitou-se aos alunos, ao final do periodo de estágio na unidade, que respondessem à questāo: "O que você pensa sobre a utilizaçāo do roteiro para a sistematização da assistência de enfermagem à gestante de alto risco desenvolvida durante o estágio? Por quê? (ANEXO II)

A opiniāo dos 15 alunos matriculados no curso de Especializaçāo em Enfermagem Obstétrica, nos anos de 1991 e 1992, foi agrupada em três categorias que podem ser verificadas no Quadro a seguir.

Quadro. Opiniāo dos alunos sobre a utilizaçāo da sistematizaçāo da assistência de enfermagem para gestantes de alto risco. Sảo Paulo, 1991/1992.

\section{Relacionada à assistência}

- útil para nos orientarmos e organizarmos nossa assistência de acordo) com as prioridades da gestante

- bom instrumento para planejar a assistência, priorizando-a e podendo me organizar 
- fornece continuidade da assistência

- fornece melhor visão da paciente

- auxilia na prestação de cuidados, pois sem um documento é mais fácil esquecer ou não prestar algum cuidado

- direciona a assistência

- promove acompanhamento geral da evolução da paciente

- possibilita avaliar a evoluçāo da paciente

- permite planejamento, organizaçāo e coordenação da assistência

- permite adequação da assistência às necessidades da paciente

- direciona melhor a assistência, individualizando, humanizando e assistindo o indivíduo como um todo.

\section{Relacionada ao ensino}

- ajuda termos visão geral dos problemas e dos cuidados em cada patologia

- possibilita correlacionar os cuidados que devem ser executados com os sinais e sintomas

- é nesse momento que paramos para pensar e relacionar as alteraçōes com a patologia ou a medicaçäo

- poderíamos não relacionar os problemas à assistência se apenas anotássemos na prescrição

- motiva a discussão dos casos e aprofundamento das patologias

- importante para a compreensão da assistència frente a patologias muito específicas

- momento em que aparecem muitas dúvidas e a necessidade de buscar informaçōes com relaçāo às condutas e cuidados de enfermagem.

\section{Relacionada à instituição}

- facilita o trabalho da enfermeira ao passar a visita diária 
- economiza tempo porque dá rapidamente o estado geral da paciente

- permite trabalho mais sistematizado e registro concreto da atuação da enfermeira e sua avaliação posterior.

Como se observa pela opiniāo expressa pelos alunos, a utilizaçāo da sistematização da assistência de enfermagem à gestante de alto risco, em regime de internação, atende às necessidades do aluno, da paciente e do serviço. Outro ponto referido pelos alunos é a necessidade do envolvimento do pessoal da instituição na sistematização da assistência, pois esta deveria ser desenvolvida pelo pessoal de enfermagem da unidade para a continuidade da assistência. Este fato pode ser verificado pelas seguintes manifestaçōes dos alunos:

"O instrumento utilizado deveria ser incorporado ao prontuário como instrumento de trabalho comunicativo, legal e assistencial";

"Proveitoso, embora pouco desanimador, pois, as prescriçōes só são desenvolvidas por nós".

A opiniāo dos alunos, verificada acima, confirma que a utilização da sistematização da assistência de enfermagem à gestante de alto risco, aplicada ao ensino de enfermagem obstétrica, proporciona so mesmo uma visão holística da gestante. Facilita, ainda, a identificação de sinais e sintomas próprios de cada patologia, a análise dos exames e tratamentos realizados e reforça a necessidade da observaçảo do binômio māe-feto para se evitar repercussóes indesejáveis no desenvolvimento da gravidez.

\section{CONCLUSĀO}

Neste estudo, a sistema tizaçāo da assistência de enfermagem às gestantes de alto risco foi avaliada por sua utilização no ensino de enfermagem obstétrica, por dois grupos de alunos do curso de Especializaçāo.

A opiniāo dos alunos confirmou o valor do emprego desta metodologia de assistência de enfermagem como estratégia de ensino, pois consideraramno um processo de grande importância para o próprio aprendizado, para o da gestante e para a instituiçāo.

Por outro lado, a nāo utilizaçāo da sistematização pela instituição, campo de prática, é um fator limitante que prejudica o aprendizado do aluno, uma vez que ele näo tem um modelo no qual possa ser inserido. Se a instituição adotasse a sistematização, o aluno teria oportunidade de contribuir e de entrosar-se nas atividades de assistência à gestante de alto risco, desenvolvidas na unidade. Acredita-se, também, que a persistência em manter a estratégia adotada para o ensino no curso de es pecialização e as reuniōes realizadas com os enfermeiros da unidade possam atuar como referência para a adoçāo da sistematizaçāo da assistência pelo serviço de enfermagem da instituiçāo. 
Finalizando, a utilizaçāo, pela instituição, da sistematização da assistência de enfermagem pode ser uma forte aliada para a elevação do padrão de assistência de enfermagem obstétrica para a diminuição da morbi-mortalidade materno-fetal.

PRAÇA, N. S. High risk pregnancy nursing care systematization: strategy to obstetric nursing teaching. Rev.Esc.Enf.USP, v.28, n.1,p. 96-104, Apr., 1994.

The present study describes a teaching experience using high risk pregnancy uncy nursing care systematization with patients of a maternity. It also shows the students dents opinion of the use of such methodology.

UNITERMS: Obstetrical nursing. Nursing process.

\section{REFERÊNCIAS BIBLIOGRÁFICAS}

HORTA, W. de A. Processo de onfermagem. São Paulo. EPU/EDUSP. 1979.

WALDOW, V.R. Processo de enfermagem: teoria e prática. Rev.Gaúcha Enf. v.9, n.1, p.14-22, 1988. 


\section{ANEXO I}

SISTEMATIZAÇĀO DA ASSISTẾNCIA DE ENFERMAGEM À GESTANTE DE ALTO RISCO Nome:

Leito:

RH:

No. de gestaçöes:

Paridade:

Tipo(s) de

Parto(s)

Filhos vivos:

DUM: $1-1$

DPP: I- I- IG:

IG: semanas

Motivo dn interançio:

Data da intornaçio: _ I I

Necenddades beficas afotadas e dados obstétricos identifleados ao primeiro exame da geatante:

Data:_L_ Nome do aluno:

$\mid$ DATA $\mid$ PRESCRIÇĀO DE ENFERMAGEM $\mid$ EVOLUÇẢO 


\begin{abstract}
ANEXO II
O que você pensa sobre a utilizaçāo do roteiro para a sistematizaçāo da assistência de enfermagem à gestante de alto risco desenvolvida durante o estágio? Por quê?
\end{abstract}

